\title{
Ethanol Extracts of Yacon and Ginger in Diet of Juvenile Olive Flounder (Paralichthys olivaceus): Effect on Growth, Feed Utilization, Body Composition, Plasma Chemistry and Challenge Test against Vibrio anguillarum
}

\author{
Lei Li Yin ${ }^{1}\left(\mathbb{D}\right.$, Sung Hwoan $\mathrm{Cho}^{1, *} \mathbb{D}^{\mathbb{D}}$, Seung-Chun Park ${ }^{2} \mathbb{D}$, Mun-Gyeong Kwon ${ }^{3}$
}

${ }^{1}$ Korea Maritime and Ocean University, Division of Marine Bioscience, Busan 49112, Korea.
${ }^{2}$ Kyungpook National University, College of Veterinary Medicine, Daegu 41566, Korea.
${ }^{3}$ National Institute of Fisheries Science, Aquatic Disease Control Division, Busan 46083, Korea.

How to cite

Yin, L.L., Cho, S.H., Park, S.C., Kwon, M.G. (2021). Ethanol Extracts of Yacon and Ginger in Diet of Juvenile Olive Flounder (Paralichthys olivaceus): Effect on Growth, Feed Utilization, Body Composition, Plasma Chemistry and Challenge Test against Vibrio anguillarum. Turkish Journal of Fisheries and Aquatic Sciences, 21, 265-274. http://doi.org/10.4194/1303-2712-v21_6_01

\section{Article History}

Received 17 December 2020

Accepted 03 March 2021

First Online 04 March 2021

\section{Corresponding Author \\ Tel.: +82514104755 \\ E-mail: chosunh@kmou.ac.kr}

\section{Keywords}

Phytic-additive

Olive flounder (Paralichthys olivaceus)

Vibrio anguillarum

Immunostimulants

\begin{abstract}
Development of natural immunostimulants as dietary additive keeps receiving scientist's interest and administration of ethanol extract of additive is one of the effective methods to concentrate their bioactive compounds to improve their effects. Dietary inclusion effect of ethanol extracts of yacon and ginger on growth, feed utilization, body composition, plasma chemistry of fish and challenge test against Vibrio anguillarum compared to a commercial probiotic (Super lacto ${ }^{\circ}$ ) was determined. Three hundred and sixty juvenile fish were distributed into $12,50 \mathrm{~L}$ flowthrough tanks. Four experimental diets were prepared. Additive-free basal diet was served as the control (CON) diet. The $1 \%$ ethanol extracts of yacon and ginger, and $0.5 \%$ Super lacto ${ }^{\circ}$ were included into the CON diet, referred to as the YCE, GGE and SUP diets, respectively. Each diet was hand-fed to triplicate groups of fish for 8 weeks. After the 8-week feeding trial, fish were injected with $V$. anguillarum and survival was monitored for the next 7 days. Dietary additives did not affect weight gain, feed utilization, whole body composition and plasma parameters of fish. Survival of fish fed the YCE and GGE diets was significantly higher than that of the fish fed the CON and SUP diets at the end of the 7-day post observation. Ethanol extracts of yacon and ginger can be effectively used as natural immunostimulants for olive flounder at occurrence of $V$. anguillarum.
\end{abstract}

\section{Introduction}

Olive flounder (Paralichthys olivaceus) is one of the most commercially important marine fish species for aquaculture in Eastern Asia, having excellent growth and abundantly raised in Korea, Japan and China (Cho et al., 2013; Kim et al., 2017). The annual aquaculture production of olive flounder reached 43,320 metric tons in 2019 (KOSIS, 2020) occupying 98\% of the domestic aquaculture market in Korea (Oh et al., 2019). Recently aquaculture farms are at high risk of mass mortality and poor growth performance of olive flounder due to frequent outbreak of infectious bacterial and viral diseases (Harikrishnan et al., 2011; Oh et al., 2019; Yang et al., 2019). Those pathogenic infections are posing severe problems in the aquaculture industries and causing huge economic losses to the fish farmers (Bulfon et al., 2015). Among the infections, vibriosis is a fatal haemorrhagic septicaemic disease in marine fish caused by several bacterial species including Vibrio anguillarum in Korea (Kim et al., 2014a).

Fish farmers generally use conventional disease controlling methods, such as administration of the synthetic antibiotics or chemotherapy drugs (Park, 
2009). However, the synthetic antibiotics are costly and have detrimental effect including environmental pollution, accumulation of the antibiotic residue in the fish tissues and food safety threats for public health (Jones et al., 2004; Cabello, 2006; Park, 2009). Hence, application of the synthetic antibiotics is not permitted by the Korean government for human consumption (Choi et al., 2010) as well as worldwide strict rules have been established to ban or minimize their use in aquaculture (Gabor et al., 2010; Hoseinifar et al., 2018). Since immunity and nutrition are closely related (Martin \& Król, 2017), dietary inclusion of environment-friendly and cost effective nonspecific immune modulatory nutrition-balanced feed is highly required as a substitute for the synthetic antibiotics in aquaculture.

Nowadays natural immunostimulants have been used as an alternative to the synthetic antibiotics for controlling fish diseases as they contain several bioactive compounds, such as alkaloids, quinone, terpinoids, lectins, polypeptides, phenolic and polyphenolic, and are also capable of improving fish growth and immunity (Bulfon et al., 2015; Vallejos-Vidal et al., 2016). Since plant-based treatments are easy to prepare and cheaper than the synthetic antibiotics (Harikrishnan et al., 2011; Hossain et al., 2019), their potential effects on growth, survival and/or antimicrobial properties of fish have been increased ( $\mathrm{Ji}$ et al., 2007a; Ji et al., 2007b; Nya \& Austin, 2009; Talpur et al., 2013; Zemheri-Navruz et al., 2019).

Yacon (Smallanthus sonchifolin) is a native fruit of the Andes (Qian et al., 2006) and contains phenolic compounds (chlorogenic, caffeic and ferulic acids), which have health promoting effect (Simonovska \& Vovk, 2003). In addition, yacon exhibits excellent antioxidant property (Yan et al., 1999) and antimicrobial activity against Bacillus subtilis (Lin et al., 2003). Improved growth performance and antibacterial activity against Streptococcus parauberis, Edwardsiella tarda and S. iniae in rockfish (Sebastes schlegeli) fed the diets containing yacon have been reported (Kim et al., 2016; Lee et al., 2016; Kim et al., 2018). However, dietary inclusion of yacon did not affect growth, but improved disease resistance of olive flounder against Streptococcus iniae (Kim et al., 2019).

Ginger (Zingiber officinale) belonging to the family Zingiberaceae is a perennial herb (Karuppiah \& Rajaram, 2012), contains gingerol, gingerdiol and gingerdione, and also possesses potential antioxidant activity (Akbarian et al., 2011). The diet supplemented with ginger achieved higher weight gain, feed utilization and lower cumulative mortality of juvenile rockfish than the control diet containing no additive against S. parauberis, E. tarda and S. iniae (Kim et al., 2016; Lee et al., 2016; Kim et al., 2018). Ameen et al. (2018) found that the aqueous extracts of ginger was the most effective in inhibiting the growth of Ichthyophonus sp. in vitro compared to linseed (Linum usitatissimum), henna (Lawsonia inermis) and white turmeric (Curcuma zedoaria) in blue tilapia (Oreochromis aureus)'s feed.
Improved growth and immunity were also observed in Sobaity sea bream (Sparidentex hasta), rainbow trout (Oncorhynchus mykiss) and Asian sea bass (Lates calcarifer) fed the diets containing ginger (Nya \& Austin, 2009; Talpur et al., 2013; Jahanjoo et al., 2018). However, Kim et al. (2019) reported that dietary inclusion of $1 \%$ yacon, ginger and blueberry powder did not improve either growth performance or feed utilization of olive flounder, but lower cumulative mortality against $S$. iniae infection after the $4^{\text {th }}$ and $8^{\text {th }}$ week feeding trial.

Lactobacillus fermentum is a live bacterium, helps to improve the growth performance and feed utilization of fish, and is actively involved in stimulating specific and non-specific immunity in fish (Allameh et al., 2017). Probiotic can prevent the outbreak of bacterial, viral and parasitic diseases in fish and shellfish (Hoseinifar et al., 2018). Lactobacillus gets more attention due to the high antagonistic activity, availability and production of extracellular enzyme (Banerjee \& Ray, 2017). Improved growth performance and disease resistance against $S$. iniae in olive flounder were achieved by oral administration of probiotic Lactococcus lactis subsp. lactis 12 compared to the control diet without supplementation of any additive (Heo et al., 2013). Therefore, Lactobacillus is a potential alternative to the synthetic antibiotics and probiotic bacterium, $L$. fermentum (Super lacto ${ }^{\circ}$ ) is commercially available in Korea.

In this study, therefore, we investigated the dietary inclusion of the ethanol extracts of yacon and ginger on the growth, feed utilization, chemical composition of the whole body and plasma chemistry of juvenile olive flounder and the challenge test against $V$. anguillarum compared to the commercial probiotic.

\section{Materials and Methods}

\section{Collection of Fish and Rearing Conditions}

Juvenile olive flounder was acclimated to the experimental conditions for 2 weeks before the initiation of the feeding trial after purchasing from a private hatchery (Uljin-gun, Gyeongsang Province, Korea). During the acclimation period, fish were hand fed with a commercial extruded pellet $(52 \%$ crude protein and $10 \%$ crude lipid; WooSung Feed Co. Ltd., Daejeon City, Korea) at the ratio of $2.0-2.5 \%$ of total biomass twice a day.

Three hundred and sixty juvenile fish (an initial body weight; $7.2 \pm 0.02 \mathrm{~g}$ ) were randomly distributed into 12, 50-L flow-through tanks (30 fish per tank). Sandfiltered seawater was supplied throughout the feeding trial at temperature ranging from 10.9-23.8ㅇ C (mean \pm SD: $20.9 \pm 1.90^{\circ} \mathrm{C}$ ) and flow rate was $1.43 \mathrm{~L} \mathrm{~min}^{-1}$ tank $^{-1}$. Proper aeration was supplied to each tank, and the photoperiod followed natural condition. Each diet was randomly assigned to triplicate tanks of fish and hand-fed twice daily at 09:00 a.m. and 5:00 p.m. at a 
visual satiation level for 8 weeks. Satiation feeding was determined by the point of cessation of voluntary feeding activity by fish. Pellet size (diameter: $2 \mathrm{~mm}$ ) was adjusted, and appropriate size pellet $(4 \mathrm{~mm})$ was fed as the fish grew. Dead fish were removed daily and the bottom of the tanks was daily cleaned.

\section{Experimental Diets}

Four experimental diets were prepared in triplicates (Table 1). Sixty percent fish meal and $7.5 \%$ fermented soybean meal were used as the protein source in the control (CON) diet. Twenty-four percent wheat flour and $4 \%$ squid liver and $2 \%$ soybean oils were used as the carbohydrate and lipid sources, respectively in the CON diet. No additive was included in the CON diet.

Yacon and ginger were purchased from Tongjong Village (Seoul, Korea) and supplied to Clinical PK \& PD LAB, College of Veterinary Medicine, Kyungpook National University (Daegu, Korea). Yacon and ginger were filtered through a filter paper (Whatsman filter paper) prior to extraction with absolute ethanol (1:10 $\mathrm{v} / \mathrm{v})$, and then concentrated under reduced pressure using a rotary evaporator. The ethanol extracts of $1 \%$ yacon and ginger and $0.5 \%$ commercial probiotic (Super lacto ${ }^{\circ}$ ) based on recommendation of the manufacturer were included into the experimental diets instead of an equal amount of water, referred to as the YCE, GGE and
SUP diets, respectively. All experimental diets satisfied the dietary nutrient requirements for olive flounder (Lee et al., 2000; Kim et al., 2002; Lee et al., 2002).

All ingredients of each diet were well mixed and pelletized by laboratory pellet extruder (Dongsung mechanics, Busan, Korea). The diets were dried at room temperature overnight and stored at $-20^{\circ} \mathrm{C}$ until use.

\section{Biological Measurements}

At the end of the 8-week feeding trial, all surviving fish in each tank were starved for $24 \mathrm{~h}$, anaesthetized by ethyl aminobenzoate at a concentration of $50 \mathrm{ppm}$, and then harvested and collectively weighed. Growth performance of fish was evaluated with the following response variables: weight gain $(\%)=($ final weight initial weight) $\times 100 /$ initial weight; specific growth rate (SGR) (\% body weight gain/day) $=[(\ln (W f)-\ln$ $(W \mathrm{i})) /$ days of feeding trial] $\times 100$, where $\ln (W f)=$ natural log of the final mean weight of fish and $\ln (W i)=$ natural log of the initial mean weight of fish. Feed efficiency ratio (FER), protein efficiency ratio (PER), protein retention (PR), condition factor (CF) and hepatosomatic index (HSI) were calculated as follows: $F E R=$ Weight gain of fish/feed consumed, $\mathrm{PER}=$ Weight gain of fish/protein consumed, $P R=$ Protein gain $\times 100 /$ protein consumed, $\mathrm{CF}=$ Fish weight $\times 100 /$ total length $^{3}$ and $\mathrm{HSI}$ $=$ Liver weight $\times 100 /$ fish weight.

Table 1. Formulation of the experimental diets (\%, DM basis)

\begin{tabular}{|c|c|c|c|c|}
\hline & \multicolumn{4}{|c|}{ Experimental diets } \\
\hline & CON & YCE & GGE & SUP \\
\hline \multicolumn{5}{|l|}{ Ingredients (\%, DM) } \\
\hline Fish meal $^{*}$ & 60 & 60 & 60 & 60 \\
\hline Fermented soybean** & 7.5 & 7.5 & 7.5 & 7.5 \\
\hline Wheat flour & 24 & 24 & 24 & 24 \\
\hline Super lacto ${ }^{\oplus * * *}$ & 0 & 0 & 0 & 0.5 \\
\hline Ethanol extracts of yacon ${ }^{* * * *}$ & & 1 & & \\
\hline Ethanol extracts of ginger ${ }^{* * * *}$ & & & 1 & \\
\hline Squid liver oil & 4 & 4 & 4 & 4 \\
\hline Soybean oil & 2 & 2 & 2 & 2 \\
\hline Choline & 0.5 & 0.5 & 0.5 & 0.5 \\
\hline Vitamin premix ${ }^{* * * * *}$ & 1 & 1 & 1 & 1 \\
\hline Mineral premix ${ }^{* * * * * *}$ & 1 & 1 & 1 & 1 \\
\hline \multicolumn{5}{|l|}{ Nutrients (\%, DM) } \\
\hline Dry matter & 98.5 & 98.2 & 97.8 & 98.1 \\
\hline Crude protein & 48.5 & 49.3 & 48.3 & 49.6 \\
\hline Crude lipid & 12.8 & 12.9 & 14.7 & 13.2 \\
\hline Ash & 13.3 & 13.9 & 13.6 & 13.5 \\
\hline
\end{tabular}

*Fish meal was purchased from Abank Co Ltd. (Seoul, Korea).

${ }^{* *}$ Fermented soybean meal was supplied by CJ CheilJedang Corp. (Seoul, Korea).

${ }^{* * *}$ Super lacto (a commercial probiotic, Lactobacillus fermentum) was purchased from Chang-Jo Biotec Co Ltd. (Jeju, Korea), which was an aqueous type and included into the experiment diets instead of the same amount of water.

${ }^{* * * *}$ Ethanol extracts of yacon and ginger were supplied from Clinical PK \& PD LAB, College of Veterinary Medicine, Kyungpook National University (Daegu, Korea) and included into the experimental diets instead of the same amount of water.

${ }^{* * * * *}$ Vitamin premix contained the following amount which were diluted in cellulose ( $\left.\mathrm{g} / \mathrm{kg} \mathrm{mix}\right)$ : L-ascorbic acid, $121.2 ; \mathrm{DL}-\alpha$-tocopheryl acetate, 18.8; thiamin hydrochloride, 2.7; riboflavin, 9.1; pyridoxine hydrochloride, 1.8; niacin, 36.4; Ca-D-pantothenate, 12.7; myo-inositol, 181.8; Dbiotin, 0.27; folic acid, 0.68; p-aminobenzoic acid, 18.2; menadione, 1.8; retinyl acetate, 0.73; cholecalciferol, 0.003 ; cyanocobalamin, 0.003 . ${ }^{* * * * * *}$ Mineral premix contained the following ingredients (g/kg mix): $\mathrm{MgSO}_{4} \cdot 7 \mathrm{H}_{2} \mathrm{O}, 80.0 ; \mathrm{NaH}_{2} \mathrm{PO}_{4} \cdot 2 \mathrm{H}_{2} \mathrm{O}, 370.0 ; \mathrm{KCl}, 130.0 ;$ ferric citrate, 40.0; $\mathrm{ZnSO}_{4} \cdot 7 \mathrm{H}_{2} \mathrm{O}, 20.0 ;$ Ca-lactate, 356.5; $\mathrm{CuCl}, 0.2 ; \mathrm{AlCl}_{3} \cdot 6 \mathrm{H}_{2} \mathrm{O}, 0.15 ; \mathrm{KI}, 0.15 ; \mathrm{Na}_{2} \mathrm{Se}_{2} \mathrm{O}_{3}, 0.01 ; \mathrm{MnSO}_{4} \cdot \mathrm{H}_{2} \mathrm{O}, 2.0 ; \mathrm{CoCl}_{2} \cdot 6 \mathrm{H}_{2} \mathrm{O}, 1.0$. 


\section{Analytical Procedures of the Experimental Diets and Fish}

After the 8-week feeding trial, 10 fish from each tank were randomly sampled and frozen at $-20^{\circ} \mathrm{C}$ for chemical analysis. Chemical analysis of the experimental diets and whole body of olive flounder was done according to AOAC (1995) method. Crude protein was measured by the Kjeldahl method (Kjeltec 2100 Distillation Unit; Foss Tecator, Hoganas, Sweden), crude lipid was determined using an ether-extraction method (Soxtec TM 2043 Fat Extraction System; Foss Tecator), moisture was determined by oven drying at $105^{\circ} \mathrm{C}$ for 24 $h$, and ash was determined using a muffle furnace at $550^{\circ} \mathrm{C}$ for $4 \mathrm{~h}$.

\section{Plasma Chemistry Analysis}

Fish were starved for $24 \mathrm{~h}$ at the end of 8-week feeding trial prior to analyzing the plasma chemistry. Five fish were randomly chosen from each tank, anesthetized with ethyl aminobenzoate at a concentration of $50 \mathrm{ppm}$ and then blood samples were taken by heparinized syringe from the caudal vein of fish. Plasma was collected after centrifugation at 7,000 $g$ for $10 \mathrm{~min}$ and stored at $-70^{\circ} \mathrm{C}$ as separate aliquots. Finally, total protein, total cholesterol, glutamic oxaloacetic transaminase (GOT), glutamic pyruvic transaminase (GPT) and triglycerides were analyzed by an automatic chemistry system (HITACHI 7180/7600210, Hitachi, Japan).

\section{Challenge Test}

At the end of 8-week feeding trial, 15 fish of externally normal appearance shown to be free from bacterial infection were selected from each tank and stocked into 12 static $50 \mathrm{~L}$ tanks. The fish were used for the $V$. anguillarum challenge and water was not exchanged. The pathogenic gram-positive $V$. anguillarum (FP5208) reference strain isolated from olive flounder was used for the challenge.

The culture suspension of $V$. anguillarum was grown on agar for $24 \mathrm{~h}$, collected, washed and suspended in sterile $0.85 \%$ saline solution, and then counted. Fish were then artificially infected by intraperitoneal injection with $0.1 \mathrm{~mL}$ of pathogenic $V$. anguillarum culture suspension containing $4.2 \times 10^{6}$ cells $/ \mathrm{ml}$. The fish were monitored for 7 days postinfection; dead fish were removed every $6 \mathrm{~h}$ for the first four days and every $12 \mathrm{~h}$ for the remainder of the study. Fish were starved throughout the 7-day challenge test.

\section{Statistical Analysis}

Significant differences among the means of treatment were determined by one-way ANOVA and Duncan's multi-range test (Duncan, 1955) using SPSS

Table 2. Survival (\%), weight gain (\%) and specific growth rate (SGR, \%/day) of the olive flounder fed the experimental diets for 8 weeks

\begin{tabular}{lccccc}
\hline Experimental diets & Initial weight (g/fish) & Final weight (g/fish) & $\begin{array}{c}\text { Survival } \\
(\%)\end{array}$ & $\begin{array}{c}\text { Weight gain } \\
(\%)\end{array}$ & $\begin{array}{c}\text { SGR }^{* *} \\
(\% / \text { day })\end{array}$ \\
\hline CON & $7.2 \pm 0.03$ & $29.6 \pm 0.38$ & $100 \pm 0.00$ & $310.2 \pm 4.20$ & $2.52 \pm 0.018$ \\
YCE & $7.2 \pm 0.02$ & $30.1 \pm 0.20$ & $100 \pm 0.00$ & $317.2 \pm 3.13$ & $2.55 \pm 0.013$ \\
GGE & $7.2 \pm 0.02$ & $30.4 \pm 0.08$ & $100 \pm 0.00$ & $320.0 \pm 0.40$ & $2.56 \pm 0.002$ \\
SUP & $7.2 \pm 0.01$ & $30.1 \pm 0.15$ & $100 \pm 0.00$ & $316.0 \pm 2.58$ & $2.55 \pm 0.011$ \\
\hline
\end{tabular}

Values (means of triplicate $\pm \mathrm{SE}$ ) with different superscripts are significantly different $(\mathrm{P}<0.05)$.

*Weight gain $(\%)=($ final weight - initial weight $) \times 100 /$ initial weight

${ }^{* *}$ SGR $(\% /$ day $)=[(\ln (W f)-\ln (W \mathrm{i})) /$ days of feeding trial $] \times 100$, where $\ln (W f)=$ natural log of the final mean weight of fish and $\ln (W \mathrm{i})=$ natural log of the initial mean weight of fish.

Refer to Table 1 for diet information.

Table 3. Feeding consumption (g/fish), feed efficiency ratio (FER), protein efficiency ratio (PER), protein retention (PR), condition factor (CF) and hepatosomatic index (HSI) of olive flounder fed the experimental diets for 8 weeks

\begin{tabular}{lcccccc}
\hline Experimental diets & Feed consumption (g/fish) & $\mathrm{FE}^{*}$ & $\mathrm{PER}^{* *}$ & $\mathrm{PR}^{* * *}$ & $\mathrm{CF}^{* * * *}$ & $\mathrm{HSI}^{* * * *}$ \\
\hline CON & $25.3 \pm 0.34$ & $0.88 \pm 0.003$ & $1.82 \pm 0.005^{\mathrm{a}}$ & $38.3 \pm 0.16$ & $0.81 \pm 0.003$ & $1.62 \pm 0.006^{\mathrm{b}}$ \\
YCE & $26.0 \pm 0.33$ & $0.88 \pm 0.003$ & $1.78 \pm 0.007^{\mathrm{b}}$ & $37.6 \pm 0.12$ & $0.80 \pm 0.003$ & $1.65 \pm 0.003^{\mathrm{a}}$ \\
GGE & $26.4 \pm 0.06$ & $0.88 \pm 0.001$ & $1.82 \pm 0.003^{\mathrm{a}}$ & $38.1 \pm 0.31$ & $0.80 \pm 0.000$ & $1.65 \pm 0.003^{\mathrm{a}}$ \\
SUP & $25.8 \pm 0.20$ & $0.89 \pm 0.002$ & $1.79 \pm 0.004^{\mathrm{b}}$ & $37.5 \pm 0.24$ & $0.81 \pm 0.003$ & $1.63 \pm 0.003^{\mathrm{a}}$ \\
\hline
\end{tabular}

Values (means of triplicate $\pm \mathrm{SE}$ ) with different superscripts are significantly different $(\mathrm{P}<0.05)$.

*Feed efficiency ratio (FER) = Weight gain of fish/feed consumed.

***otein efficiency ratio (PER) = Weight gain of fish/protein consumed.

*** Protein retention $(P R)=$ Protein gain $\times 100 /$ protein consumed .

${ }^{* * * *}$ Condition factor $(\mathrm{CF})=$ Fish weight $\times 100 /$ total length $^{3}$.

${ }^{* * * * *}$ Hepatosomatic index $(\mathrm{HSI})=$ Liver weight $\times 100 /$ fish weight.

Refer to Table 1 for diet information. 
program version 19.0 (SPSS Michigan Avenue, Chicago, IL, USA). All percentage data were arcsine-transformed prior to statistical analysis. Survival of fish during the 7day post observation period after $S$. iniae infection was analyzed by using Kaplan-Meier survival curve, Log-rank and Wilcoxon tests.

\section{Results}

All fish remained alive at the end of the 8-week feeding trial (Table 2). Weight gain ranging from 310.2 to $320.0 \%$ and SGR ranging from 2.52 to $2.56 \%$ /day were not significantly $(P>0.05)$ different among the experimental diets.

Feed consumption ( $\mathrm{g} / \mathrm{fish}$ ) ranging from 25.3 to $26.4 \mathrm{~g}$, FER ranging from 0.88 to 0.89 , PR ranging from 37.5 to 38.3 and CF ranging from 0.80 to 0.81 were not significantly $(P>0.05)$ affected by the experimental diets (Table 3).

Significantly $(P<0.05)$ higher protein efficiency ratio (PER) was achieved in fish fed the CON and GGE diets than that of fish fed the SUP and YCE diets. Significantly $(P<0.05)$ lower HSI was obtained in fish fed the CON diet than that of fish fed all other diets.

Dry matter ranging from 29.7 to $29.9 \%$, crude protein ranging from 65.6 to $65.8 \%$, crude lipid ranging from 8.8 to $9.0 \%$, and ash content ranging from 14.0 to $14.7 \%$ of the whole body of fish were not significantly ( $P>0.05$ ) affected by the experimental diets (Table 4).

The plasma total protein ranging from 3.24 to 4.49 $\mathrm{g} / \mathrm{dL}$, total cholesterol ranging from 173.3 to 208.0 $\mathrm{mg} / \mathrm{dL}$, GOT ranging from 42.7 to $68.0 \mathrm{IU} / \mathrm{L}, \mathrm{GPT}$ ranging from 2.0 to $2.7 \mathrm{IU} / \mathrm{L}$ and triglyceride ranging from 174.3 to $338.7 \mathrm{mg} / \mathrm{dL}$ were not significantly $(P>0.05)$ affected by the experimental diets (Table 5).

Mortality of olive flounder started to show at $42 \mathrm{~h}$ after $V$. anguillarum infection after the 8-week feeding trial (Figure 1). Fish fed the YCE and GGE diets showed significantly higher survival than that of fish fed the CON and SUP diets at the end of the 7-day post observation after infection of $V$. anguillarum $(P<0.005$ for Log-rank test).

\section{Discussion}

As frequent outbreak of bacterial, fungal and viral diseases have become a primary constraint to sustainable aquaculture production because of the associated risk of economic losses and food security in Korea (Shin et al., 2006; Jung et al., 2008; Harikrishnan et al., 2011) as well as in the worldwide (Leung \& Bates, 2013; Bulfon et al., 2015; FAO, 2019), plant-based remedy is a promising way to treat infectious fish diseases and has received increasing attention worldwide (Yilmaz, 2019; Zemheri-Navruz et al., 2019). Yacon and ginger are rich in some anti-oxidative and antimicrobial compounds (Yan et al., 1999; Lin et al., 2003; Ghasemzadeh et al., 2010; Talpur et al., 2013; Sugahara et al., 2015; Kim et al., 2016; Kim et al., 2018) and are potential substitutes for the synthetic antibiotics in aquafeed to enhance the non-specific immunity of fish.

Growth performance (weight gain and SGR) of olive flounder were not affected by the experimental diets in this study, being coincidence with other studies showing that none of the dietary additives [5\% kelp meal, $10 \%$ krill meal, $3 \%$ onion, $1 \%$ of each garlic, citrus, ginger, mugwort, licorice and wasabi powder, and the mixture of $0.2 \%$ of garlic, citrus, ginger, mugwort, licorice and wasabi and $0.5 \%$ onion) (Kim et al., 2011) or 6\% Sargassum fusiforme and Ecklonia cava powder (Kim et al., 2014b)] affected the growth performance and feed efficiency of juvenile olive flounder. Similarly, Cho et al. (2013) demonstrated that the survival and weight gain of olive flounder were not improved by the dietary inclusion of Scutellaria baicalensis extract, but the SGR was higher in fish fed the diet containing $2 \% \mathrm{~S}$. baicalensis extract compared to that of fish fed the diets

Table 4. Proximate composition (\%, dry matter basis) of the whole body of olive flounder fed the experimental diets for 8 weeks

\begin{tabular}{lcccc}
\hline Experimental diets & Dry matter & Crude protein & Crude lipid & Ash \\
\hline CON & $29.8 \pm 0.09$ & $65.7 \pm 0.14$ & $8.9 \pm 0.11$ & $14.3 \pm 0.24$ \\
YCE & $29.9 \pm 0.09$ & $65.6 \pm 0.22$ & $9.0 \pm 0.15$ & $14.7 \pm 0.14$ \\
GGE & $29.7 \pm 0.10$ & $65.8 \pm 0.43$ & $8.8 \pm 0.22$ & $14.2 \pm 0.34$ \\
SUP & $29.8 \pm 0.08$ & $65.6 \pm 0.10$ & $8.9 \pm 0.10$ & $14.0 \pm 0.18$ \\
\hline
\end{tabular}

Values (means of triplicate $\pm \mathrm{SE}$ ) with different superscripts are significantly different $(\mathrm{P}<0.05)$.

Refer to Table 1 for diet information.

Table 5. Plasma chemistry of olive flounder fed the experimental diets for 8 weeks

\begin{tabular}{llllll}
\hline $\begin{array}{l}\text { Experimental } \\
\text { diets }\end{array}$ & $\begin{array}{l}\text { Total protein } \\
(\mathrm{g} / \mathrm{dL})\end{array}$ & $\begin{array}{l}\text { Total cholesterol } \\
(\mathrm{mg} / \mathrm{dL})\end{array}$ & $\begin{array}{l}\text { GOT } \\
(\mathrm{IU} / \mathrm{L})\end{array}$ & $\begin{array}{l}\text { GPT } \\
(\mathrm{IU} / \mathrm{L})\end{array}$ & Triglyceride $(\mathrm{mg} / \mathrm{dL})$ \\
\hline CON & $3.24 \pm 0.11$ & $208.0 \pm 3.21$ & $42.7 \pm 5.81$ & $2.3 \pm 0.33$ & $174.3 \pm 18.84$ \\
YCE & $3.26 \pm 0.10$ & $196.3 \pm 3.76$ & $54.3 \pm 4.98$ & $2.0 \pm 0.58$ & $287.3 \pm 90.36$ \\
GGE & $3.41 \pm 0.22$ & $189.3 \pm 12.72$ & $68.0 \pm 3.51$ & $2.3 \pm 0.33$ & $231.7 \pm 37.57$ \\
SUP & $4.49 \pm 0.54$ & $173.3 \pm 14.50$ & $57.0 \pm 8.14$ & $2.7 \pm 0.67$ & $338.7 \pm 105.53$ \\
\hline
\end{tabular}

Values (means of triplicate \pm SE) with different superscripts are significantly different $(P<0.05)$.

Refer to Table 1 for diet information. 


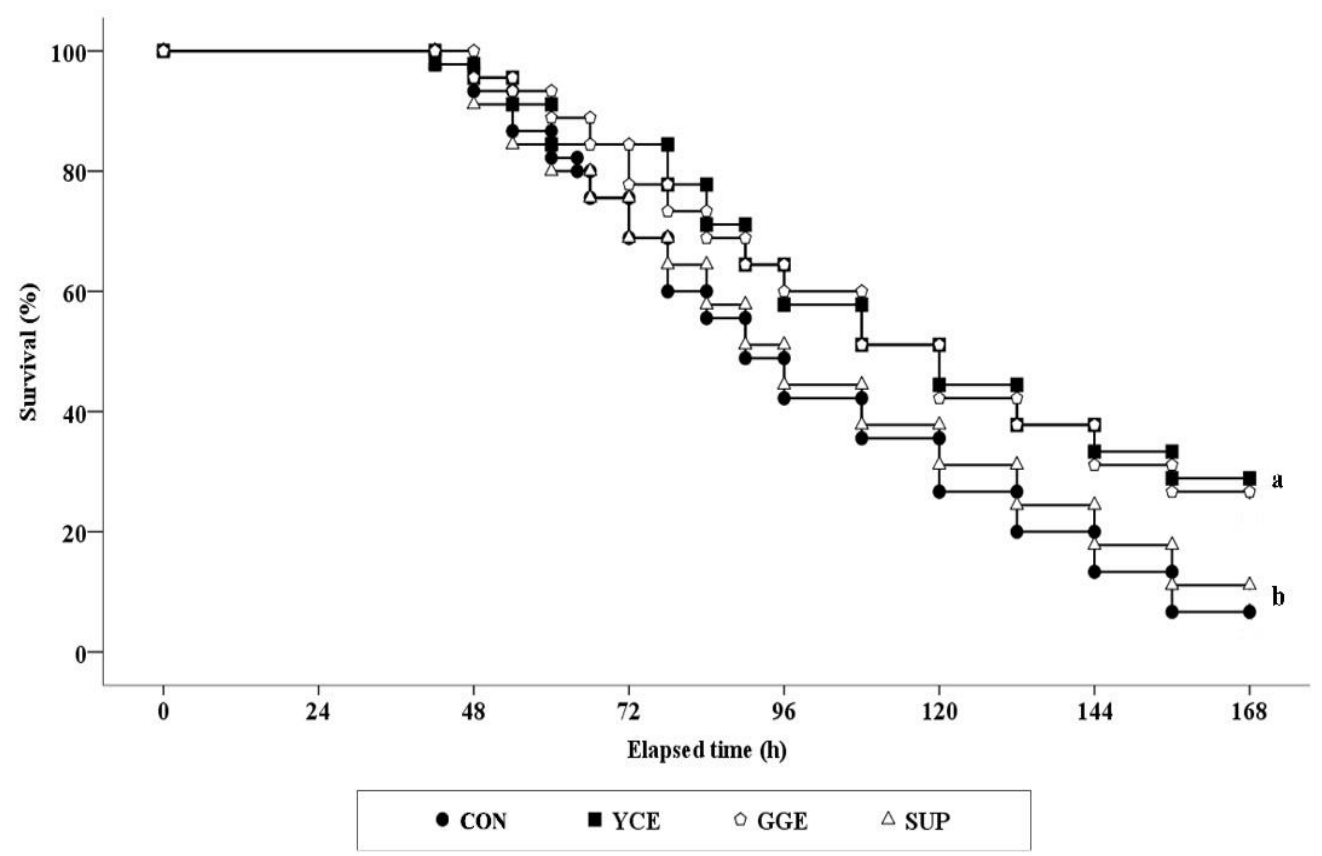

Figure 1. Kaplan-Meier survival curves of juvenile olive flounder infected with Vibrio anguillarum after the 8-week feeding trial (means of triplicate \pm SE) (Different letters within the same elapsed time indicated the significant differences among the experimental diets at the significance level of $\mathrm{P}=0.05)$. Refer to Table 1 for diet information ( $<0.005$ for Log-rank test).

containing other concentration $(0,0.5,1,3$ and $5 \%$ of $S$. baicalensis extract) for 8 weeks. Conversely, Kim et al. (2018) showed that rockfish fed the diets containing $1 \%$ yacon, ginger and blueberry exhibited higher weight gain compared to that of fish fed the control diet containing $0.01 \%$ commercial antioxidant (ethoxyquin) in the 8-week feeding trial. The differences in growth performance of fish could be related with the fish species, dose and type (powder or liquid) of additives and the nutritional or physiological state of fish (Harikrishnan et al., 2011; Kim et al., 2013b; Kim et al., 2019).

No differences were found in feed consumption, FER and PR of olive flounder in this study. Similarly, Kim et al. (2019) reported that dietary inclusion of $1 \%$ yacon, ginger and blueberry powder did not affect either growth performance or feed utilization of olive flounder. Kim et al. (2014b) also reported that the feed consumption, FE and PER of olive flounder were not affected by the dietary inclusion of $S$. fusiforme and $E$. cava powder in the 6-week feeding trial. Feed utilization of fish was also unaffected by dietary inclusion of phytoadditives (ginger, garlic, citrus, onion, mugwort, licorice, wasabi and S. baicalensis extracts) (Cho et al., 2007; Kim et al., 2011). Unlike these studies, however, feed utilization (feed consumption, FER, PER and PR) of rainbow trout and olive flounder was largely affected by the dietary inclusion of ginger and yacon (Nya \& Austin, 2009; Kim et al., 2016; Lee et al., 2016; Kim et al., 2018).

Lower HSI of fish fed the CON diet compared to all the other diets (SUP, YCE and GGE) in this study supported by Kim et al. (2013a)'s study showing that the HSI was higher in olive flounder fed the diets containing various chemical additives, such as solid sulfur ( 0.5 and $1 \%)$, fucoidan $(0.2$ and $0.4 \%)$ and glucan $(0.1 \%)$ compared to that of fish fed the control diet with no additive in the 6-week feeding trial. In contrast, Cho et al. (2007) showed that greater HSI was found in olive flounder fed the control diet with no additive compared to the diets containing various sources of green tea. However, further research will facilitate to find out the precise reason behind the higher HSI in olive flounder fed the phyto-additives.

None of the whole body chemical composition, plasma total protein, cholesterol, GOT, GPT and triglyceride level was affected by the experimental diets in this study. Similarly, the chemical composition and plasma chemistry of fish was not affected by dietary inclusion of additives (Kim et al., 2019). In addition, insignificant effect on the proximate composition ( $\mathrm{Ji}$ et al., 2007a) and plasma chemistry (Cho et al., 2013) of olive flounder fed the diets containing medicinal herb mixture (Massa medicata fermentata: Crataegi fructus: Artemisia capillaris: Cnidium officinale $=2: 2: 1: 1$ ) and $S$. baicalensis extract have been reported. Unlike these studies, however, dietary inclusion of various phytoadditives affected the chemical composition (Hwang et al., 2013; Kim et al., 2016) and plasma chemistry of fish (Cho et al., 2007; Nya \& Austin, 2009; Talpur et al., 2013; Jahanjoo et al., 2018).

Higher survival of olive flounder fed the YCE and GGE diets after experimental infection of $V$. anguillarum 
at the end of 7-day post observation compared to that of fish fed the CON and SUP diets indicated that administration of the ethanol extracts of yacon and ginger were more resistant against $V$. anguillarum than the commercial probiotic (Super lacto ${ }^{\circ}$ ), supported by Kim et al. (2014b)'s study showing that the dietary inclusion of S. fusiforme and E. cava powder did not affect the growth performance and feed utilization of olive flounder, but achieved higher disease resistance against $E$. tarda compared to that of fish fed the control diet and the diet containing $0.5 \%$ oxytetracycline at the $4^{\text {th }}$ day after injection although none of the experimental group showed any difference in mortality in the end of 15-day challenge test. Antibacterial activity of ginger essential oil (1:1 = pure oil: dimethyl sulfoxide) against major bacterial pathogens (Photobacterium damselae, Lactococcus garvieae, S. iniae and $S$. parauberis) of olive flounder have been reported, which are resistant to one or more commonly used the synthetic antibiotic, such as ampicillin, tetracycline, chloramphenicol and erythromycin (Hossain et al., 2019). Kim et al. (2019) also reported that yacon and ginger played as immunostimulants for olive flounder and achieved comparable survival to fish fed a diet containing $0.5 \%$ probiotic of $L$. fermentum after $S$. ininae infection during the 8-day post observation after the 8week feeding trial.

Unlike this study, however, administration of yacon and ginger improved not only growth performance, but also immune responses of different species of fish infected with different pathogens (Nya \& Austin, 2009; Talpur et al., 2013; Kim et al., 2016; Lee et al., 2016; Kim et al., 2018; Jahanjoo et al., 2018). In considering the results (Kim et al., 2016; Lee et al., 2016; Kim et al., 2018) that oral administration of yacon and ginger not only improved growth performance and feed utilization, but also disease resistance of rockfish and the results of Kim et al. (2019)'s study and this study showing that inclusion of their ethanol extractions in diets did not affect either growth performance or feed utilization, but just improved disease resistance of olive flounder. Although we had not compared dietary inclusion effect of ethanol extraction of yacon and ginger on rockfish, yacon and ginger seemed to play as both growth promoter and immunostimulants for rockfish, but only immunostimulants for olive flounder. Desirable effect of dietary inclusion of yacon and ginger appeared to have priority in the experimental fish species tested rather than their extraction method. The biological compounds, such as fluctuanin exhibiting the strongest antibacterial activity against Bacillus subtilis (Lin et al., 2003) and chlorogenic acid having a strong antioxidant property (Sugahara et al., 2015) in yacon, and zingiberene having immunoenhancing activity in ginger (Zakaria-Rungkat et al., 2003) seemed to play as immunostimulants for olive flounder in this study.

Improved growth performance and immunological activity of Nile tilapia ( $O$. niloticus) fed the diet containing $1.5 \%$ blueberry syrup compared to the control diet and the diet containing $0.002 \%$ antibiotic (Flormis Aqua $^{\odot}$ ) against Plesiomonas shigelloides have been reported (Yilmaz, 2019). Talpur et al. (2013) explained that oral administration of various concentrations $(0.1,0.2,0.3,0.5$ and $1 \%)$ of ginger increased survival of Asian sea bass infected with $V$. harveyi and modulated plasma lysozyme activity, phagocytic activity of the head kidney macrophages and serum anti-protease activity. Disease resistant capacity of fish fed the diets containing yacon and ginger was also reported against artificial infection of different pathogenic bacteria (Sebiomo et al., 2010; Kim et al., 2016; Lee et al., 2016; Kim et al., 2018). Therefore, relatively lower cumulative mortality of olive flounder fed the YCE and GGE diets compared to fish fed the CON and SUP diets at the end of 7-day post observation in this study can be related with the presence of different biologically active compounds, which accelerate immune activity and inhibit pathogenic aggregation, supported by several other studies showing that ginger improved the phagocytic and lysozyme activity of fish (Nya \& Austin, 2009; Talpur et al., 2013; Jahanjoo et al., 2018), and yacon showed efficacy at occurrence of various pathogenic bacteria (Kim et al., 2007a, 2016; Lee et al., 2016)

Although the growth, feed utilization (FER and PR), chemical composition and plasma chemistry of olive flounder were not affected by dietary inclusion of the ethanol extracts of yacon and ginger in the 8-week feeding trial, they effectively lowered the cumulative mortality of olive flounder infected with $V$. anguillarum compared to the CON diet or the diet containing commercial probiotic (Super lacto ${ }^{\circledR}$ ). Therefore, the ethanol extracts of yacon and ginger seem to play as natural immunostimulant against $V$. anguillarum in olive flounder. Further research is needed to determine the effect of different doses of the ethanol extracts of yacon and ginger on growth performance and immune response of olive flounder against other pathogens.

\section{Ethical Statements}

Not applicable.

\section{Funding Information}

This work was supported by the National Research Foundation of Korea (NRF) grant funded by the Korean government (No. 2020R1A2C1009903). This work was also supported by a grant National Institute of Fisheries Sciences (NIFS), Republic of Korea (R2020060).

\section{Author Contribution}

Lei Li Yin ran the feeding trial and analyzed the samples. Sung Hwoan Cho designed the study and prepared the draft. Seung-Chun Park supplied extracts of additives. Mun-Gyeong Kwon supplied pathogen. All authors have read and approved the manuscript. 


\section{Conflict of Interest}

The authors declare no conflict of interest.

\section{Acknowledgements}

This work was supported by the National Research Foundation of Korea (NRF) grant funded by the Korean government (No. 2020R1A2C1009903). This work was also supported by a grant National Institute of Fisheries Sciences (NIFS), Republic of Korea (R2020060).

\section{References}

Akbarian, A., Golian, A., Ahmadi, A.S., \& Moravej, H. (2011). Effects of ginger root (Zingiber officinale) on egg yolk cholesterol, antioxidant status and performance of laying hens. Journal of Applied Animal Research, 39, 1921. https://doi.org/10.1080/09712119.2011.558612

Allameh, S.K., Noaman, V., \& Nahavandi, R. (2017). Effects of probiotic bacteria on fish performance. Advance Techniques in Clinical Microbiology, 1, 11.

Ameen, F., Al-Niaeem, K., Taher, M.M., \& Sultan, F.H. (2018). Potential of plant extracts to inhibit the Ichthyophonus sp. infection in blue tilapia: A preliminary study in vitro. National Academy Science Letters, 41, 129-132.

AOAC (Association of Official Analytical Chemists). (1995). Official Methods of Analysis. Arlington, VA, pp. 382.

Banerjee, G., \& Ray, A.K. (2017). The advancement of probiotics research and its application in fish. Research in Veterinary Science, 115, 66-77. https://doi.org/10.1016/j.rvsc.2017.01.016

Bulfon, C., Volpatti, D., \& Galeotti, M. (2015). Current research on the use of plant-derived products in farmed fish. Aquaculture Research, 46, 513-551. https://doi.org/10.1111/are.12238

Cabello, F.C. (2006). Heavy use of prophylactic antibiotics in aquaculture: a growing problem for human and animal health and for the environment. Environmental Microbiology, 8, 1137-1144. https://doi.org/10.1111/j.1462-2920.2006.01054.x

Cho, S.H., \& Lee, S. (2012). Onion powder in the diet of the olive flounder, Paralichthys olivaceus: effects on the growth, body composition, and lysozyme activity. Journal of the World Aquaculture Society, 43, 30-38. https://doi.org/10.1111/j.1749-7345.2011.00489.x|

Cho, S.H., Lee, S., Park, B.H., Ji, S., Lee, J., Bae, J., \& Oh, S. (2007). Effect of dietary inclusion of various sources of green tea on growth, body composition and blood chemistry of the juvenile olive flounder, Paralichthys olivaceus. Fish Physiology and Biochemistry, 33, 49-57. https://doi.org/10.1007/s10695-006-9116-3

Cho, S.H., Jeon, G.H., Kim, D.S., \& Kim, C. (2013). Effects of dietary Scutellaria baicalensis extract on growth, feed utilization and challenge test of olive flounder (Paralichthys olivaceus). Asian-Australasian Journal Animal Science, 26, 90-96. https://doi.org/10.5713/ajas.2012.12147

Choi, J.G., Kang, O.H., Lee, Y.S., Oh, Y.C., Chae, H.S., Obiangobounou, B., Park, S.C., Shin, D.W., Hwang, B.Y., \& Kwon, D.Y. (2010). Antimicrobial activity of the constituents of Smallanthus sonchifolius leaves against methicillinresistant Staphylococcus aureus. European Review for Medical and Pharmacological Sciences, 14, 1005-1009.
Duncan, D.B. (1995). Multiple range and multiple $F$ tests. Biometrics, 11, 1-42.

FAO (Food and Agricultural Organization) (2019). Information and analysis on world fish trade. Rome Italy: Author.

Gabor, E., Sara, A., \& Barbu, A. (2010). The effects of some phytoadditives on growth, health and meat quality on different species of fish. Scientific Papers Animal Science and Biotechnologies, 43, 61-65.

Ghasemzadeh, A., Jaafar, H.Z.E., Rahmat, A., Wahab, P.E.M., \& Halim, M.R.A. (2010). Effect of different light intensities on total phenolics and flavonoids synthesis and antioxidant activities in young ginger varieties (Zingiber officinale Roscoe). International Journal of Molecular Sciences, 11, 3885-3897. https://doi.org/10.3390/ijms11103885

Harikrishnan, R., Balasundaram, C., \& Heo, M.S. (2011). Impact of plant products on innate and adaptive immune system of cultured finfish and shellfish. Aquaculture, 317,1-15.

https://doi.org/10.1016/j.aquaculture.2011.03.039

Heo, W., Kim, Y., Bai, S.C., \& Kong, I. (2013). Effects of dietary probiotic, Lactococcus lactis subsp. lactis 12 supplementation on the growth and immune response of olive flounder (Paralichthys olivaceus). Aquaculture, 376-379, 20-24.

https://doi.org/10.1016/j.aquaculture.2012.11.009

Hoseinifar, S.H., Sun, Y.Z., Wang, A., \& Zhou, Z. (2018). Probiotics as means of disease control in aquaculture, a review of current knowledge and future perspectives. Frontiers in Microbiology, 9, 2429. https://doi.org/10.3389/fmicb.2018.02429

Hossain, S., De Silva, B.C.J., Wimalasena, S.H.M.P., Pathirana, H.N.K.S., \& Heo, G.J. (2019). In vitro antibacterial effect of ginger (Zingiber officinale) essential oil against fish pathogenic bacteria isolated from farmed olive flounder (Paralichthys olivaceus) in Korea. Iranian Journal of Fisheries Sciences, 18, 386-394. https://doi.org/10.22092/ijfs.2018.119853

Hwang, J.H., Lee, S.W., Rha, S.J., Yoon, H.S., Park, E.S., Han, K.H., \& Kim, S.J. (2013). Dietary green tea extract improves growth performance, body composition, and stress recovery in the juvenile black rockfish, Sebastes schlegeli. Aquaculture International, 21, 525-538. https://doi.org/10.1007/s10499-012-9586-5

Jahanjoo, V., Yahyavi, M., Akrami, R., \& Bahri, A.H. (2018). Influence of adding garlic (Allium sativum), ginger (Zingiber officinale), thyme (Thymus vulgaris) and their combination on the growth performance, haemato immunological parameters and disease resistance to Photobacetrium damselae in Sobaity sea bream (Sparidentex hasta) fry. Turkish Journal of Fisheries and Aquatic Sciences, 18, 633-645. https://doi.org/10.4194/1303-2712-v18_4_15

Ji, S., Jeong, G., Im, G., Lee, S., Yoo, J., \& Takii, K. (2007a). Dietary medicinal herbs improve growth performance, fatty acid utilization, and stress recovery of Japanese flounder. Fisheries Science, 73, 70-76. https://doi.org/10.1111/j.1444-2906.2007.01303.x

Ji, S., Takaoka, O., Jeong, G., Lee, S., Ishimaru, K., Seoka, M., \& Takii, K. (2007b). Dietary medicinal herbs improve growth and some non-specific immunity of red sea bream Pagrus major. Fisheries Science, 73, 63-69. https://doi.org/10.1111/j.1444-2906.2007.01302.x

Jones, O.A, Voulvoulis, N., \& Lester, J.N. (2004). Potential ecological and human health risks associated with the 
presence of pharmaceutically active compounds in the aquatic environment. Critical Reviews in Toxicology, 34, 335-350. https://doi.org/10.1080/10408440490464697

Jung, S., Kim, S., Joung, I., Kitamura, S., Ceong, H., \& Oh, M. (2008). Distribution of marine birnavirus in cultured olive flounder Paralichthys olivaceus in Korea. The Journal of Microbiology, 46, 256-273.

https://doi.org/10.1007/s12275-008-0004-7

Karuppiah, P., \& Rajaram, S. (2012). Antibacterial effect of Allium sativum cloves and Zingiber officinale rhizomes against multiple-drug resistant clinical pathogens. Asian Pacific Journal of Tropical Biomedicine, 2, 597-601. https://doi.org/10.1016/S2221-1691(12)60104-X

Kim, K.D., Lee, S., Park, H.G., Bai, S.C., \& Lee, Y.H. (2002). Essentiality of dietary $n-3$ highly unsaturated fatty acids in juvenile Japanese flounder (Paralichthys olivaceus). Journal of the World Aquaculture Society, 33, 432-440. https://doi.org/10.1111/j.1749-7345.2002.tb00022.x

Kim, K.D., Seo, J.Y., Hong, S.H., Kim, J.H., Byun, H.G., Kim, K.W., Son, M.H., \& Lee, S.M. (2011). Effects of dietary inclusion of various additives on growth performance, hematological parameters, fatty acid composition, gene expression and histopathological changes in juvenile olive flounder Paralichthys olivaceus. Korean Journal of Fisheries and Aquatic Science, 44, 141-148. https://doi.org/10.5657/kfas.2011.44.2.141

Kim, K., Kim, K., Lee, B., Lee, J., Bai, S.C., Choi, Y., \& Han, H. (2013a). Effects of dietary inclusion of various additives on growth performance and immune responses in juvenile olive flounder (Paralichthys olivaceus). Journal of Fisheries and Marine Sciences Education, 25, 12851293. https://doi.org/10.13000/JFMSE.2013.25.6.1285

Kim, K.T., Jeon, G.H., Cho, S.H., Lim, S.G., \& Kwon, M. (2013b). Effect of dietary inclusion of various concentrations of Scutella baicalensis Georgi extract on growth, body composition, serum chemistry and challenge test of far eastern catfish (Silurus asotus). Aquaculture Research, 44, 1502-1510. https://doi.org/10.1111/j.13652109.2012.03157.x

Kim, S.M., Jun, L.J., Yeo, I.K., Jeon, Y.J., Lee, K.J., Jeong, H.D., \& Jeong, J.B. (2014a). Effects of dietary supplementation with garlic extract on immune responses and diseases resistance of olive flounder, Paralichthys olivaceus. Journal of Fish Pathology, 27, 35-45. https://doi.org/10.7847/jfp.2014.27.1.035

Kim, K.W., Kim, S.S., Khosravi, S., Rahimnejad, S., \& Lee, K.J. (2014b). Evaluation of Sargassum fusiforme and Ecklonia cava as dietary additives for olive flounder (Paralichthys olivaceus). Turkish Journal of Fisheries and Aquatic Sciences, 14, 321-330. https://doi.org/10.4194/13032712-v14_2_03

Kim, H.S., Kim, H.J., Choi, D.G., Jang, B., Cho, S.H., Kwon, M., Min, B., \& Kim, D.S. (2016). Effect of various sources of dietary additives on growth, body composition, and 1 challenge test survival of juvenile rockfish Sebastes schlegeli. Turkish Journal of Fisheries and Aquatic Sciences, 16, 759-766. https://doi.org/10.4194/13032712-v16_4_02

Kim, K., Kim, K., Han, H., Won, S., Moniruzzaman, M., Lee, J., Choi, Y.H., \& Bai, S.C. (2017). Evaluation of the dietary protein requirement of a selectively bred (F-5 generation) strain of olive flounder, Paralichthys olivaceus. Turkish Journal of Fisheries and Aquatic Sciences, 17, 1009-1016. https://doi.org/10.4194/13032712-v17_5_16
Kim, H.S., Lee, K.W., Jung, H.S., Kim, J., Yun, A., Cho, S.H., \& Kwon, M. (2018). Effects of dietary inclusion of yacon, ginger and blueberry on growth, body composition and challenge test of juvenile rockfish (Sebastes schlegeli) against Edwardsiella tarda. Aquaculture Nutrition, 24, 1048-1055. https://doi.org/10.1111/anu.12643

Kim, J., Lee, K.W., Jeong, H.S., Ansary, M.W.R., Kim, H.S., Kim, T., Kwon, M., \& Cho, S.H. (2019). Oral administration effect of yacon, ginger and blueberry on the growth, body composition and plasma chemistry of juvenile olive flounder (Paralichthys olivaceus) and immunity test against Streptococcus iniae compared to a commercial probiotic, Lactobacillus fermentum. Aquaculture Reports, 15, 10021.

https://doi.org/10.1016/j.aqrep.2019.100212

KOSIS. (2020) Korean statistical information service. Daejeon, Korea.

Lee, S., Cho, S.H., \& Kim, K.D. (2000). Effects of dietary protein and energy levels on growth and body composition of juvenile flounder Paralichthys olivaceus. Journal of the World Aquaculture Society, 31, 306-316. https://doi.org/10.1111/j.1749-7345.2000.tb00882.x

Lee, S., Park, C.S., \& Bang, I.C. (2002) Dietary protein requirement of young Japanese flounder Paralichthys olivaceus fed isocaloric diets. Fisheries Science, 68, 158164. https://doi.org/10.1046/j.14442906.2002.00402.x|

Lee, K.W., Kim, H.S., Cho, S.H., Park, C., \& Ha, M. (2016). Effect of dietary inclusion of yacon, ginger and blueberry on growth, feed utilization, serum chemistry and challenge test against Streptococcus iniae of juvenile rockfish Sebastes schlegeli. Korean Journal of Fisheries and Aquatic Science, 49, 823-829. https://doi.org/10.5657/KFAS.2016.0823

Leung, T.L.F., \& Bates, A.E. (2013). More rapid and severe disease outbreaks for aquaculture at the tropics: implications for food security. Journal of Applied Ecology, 50, 215-222. https://doi.org/10.1111/13652644.12017

Lin, F., Hasegawa, M., \& Kodama, O. (2003). Purification and identification of antimicrobial sesquiterpene lactones from yacon (Smallanthus sonchifolius) leaves. Bioscience, Biotechnology, and Biochemistry, 67, 21542159. https://doi.org/10.1271/bbb.67.2154

Martin, S.A.M., \& Król, E. (2017). Nutrigenomics and immune function in fish: new insights from omics technologies. Developmental and Comparative Immunology, 75, 8698. https://doi.org/10.1016/j.dci.2017.02.024

Mohammadi, G., Rashidian, G., Hoseinifar, S.H., Naserabad, S.S., \& Doan, H.V. (2020). Ginger (Zingiber officinale) extract affect growth performance, body composition, haematology, serum and mucosal immune parameters in common carp (Cyprinus carpio). Fish and Shellfish Immunology, 99, 267-273. https://doi.org/10.1016/j.fsi.2020.01.032

Nya, E.J., \& Austin, B. (2009). Use of dietary ginger, Zingiber officinale Roscoe, as an immunostimulant to control Aeromonas hydrophila infections in rainbow trout, Oncorhynchus mykiss (Walbaum). Journal of Fish Diseases, 32, 971-977. https://doi.org/10.1111/j.13652761.2009.01101.x

Oh, J.Y., Kim, E.A., Lee, H., Kim, H.S., Lee, J.S., \& Jeon, Y.J. (2019). Antihypertensive effect of surimi prepared from olive flounder (Paralichthys olivaceus) by angiotensin-I converting enzyme (ACE) inhibitory activity and 
characterization of ACE inhibitory peptides. Process Biochemistry, 80, 164-170.

https://doi.org/10.1016/j.procbio.2019.01.016

Park, S.I. (2009). Disease control in Korean aquaculture. Fish Pathology, 44, 19-23. https://doi.org/10.3147/jsfp.44.19

Qian, L., Ding, C.L.L., \& Cai, L. (2006). The component and functionality of yacon. Food Research and Development, 27,179-180.

Sebiomo, A., Awofodu, A.D., Awosanya, A.O., Awotona, F.E., \& Ajayi, A.J. (2010). Comparative studies of antibacterial effect of some antibiotics and ginger (Zingiber officinale) on two pathogenic bacteria. Journal of Microbiology and Antimicrobials, 3, 18-22.

Shin, G.W., Palaksha, K.J., Yang, H.H., Shin, Y.S., Kim, Y.R., Lee, E.Y., Kim, H.Y., Kim, Y.J., Oh, M.J., Yoshida, T., \& Jung, T.S. (2006). Discrimination of streptococcosis agents in olive flounder (Paralichthys olivaceus). Bulletin of the European Association of Fish Pathology, 26, 68-79.

Simonovska, B., \& Vovk, I. (2003). Investigation of phenolic acids in yacon (Smallanthus sonchifolius) leaves and tubers. Journal of Chromatography A, 1, 89-98. https://doi.org/10.1016/s0021-9673(03)01183-x

Sugahara, S., Ueda, Y., Fukuhar, K., Kamauta, Y., Matsuda, Y., Murata, T., Kuroda, Y., Kabata, K., Ono, M., Igoshi, K., \& Yasuda, S. (2015). Antioxidant effects of herbal tea leaves from yacon (Smallanthus sonchifolius) on multiple free radical and reducing power assays, especially on different superoxide anion radical generation systems. Journal of Food Science, 80, c2420-c2429. https://doi.org/10.1111/1750-3841.13092

Talpur, A.D., Ikhwanuddin, M., \& Bolong, A.A. (2013). Nutritional effects of ginger (Zingiber officinale Roscoe) on immune response of Asian sea bass, Lates calcarifer (Bloch) and disease resistance against Vibrio harveyi. Aquaculture, 400, 46-52. https://doi.org/10.1016/j.aquaculture.2013.02.043

Vallejos-Vidal, E., Reyes-Lopez, F., Teles, M., \& Mackenzie, S. (2016). The response of fish immunostimulant diets. Fish and Shellfish Immunology, 56, 34-69. https://doi.org/10.1016/j.fsi.2016.06.028

Yan, X.J., Suzuki, M., Ohnishi-Kameyama, M., Sada, Y., Nakanishi, T., \& Nagata, T. (1999). Extraction and identification of antioxidants in the roots of yacon (Smallanthus sonchifolius). Journal of Agriculture and Food Chemistry, 47, 4711-4713. https://doi.org/10.1021/jf981305o

Yang, Y., Park, J., You, S.G., \& Hong, S. (2019). Immunostimulatory effects of sulfated polysaccharides isolated from Codium fragile in olive flounder, Paralichthys olivaceus. Fish and Shellfish Immunology, 87, 609-614. https://doi.org/10.1016/j.fsi.2019.02.002

Yilmaz, S. (2019). Effects of dietary blackberry syrup supplement on growth performance, antioxidant, and immunological responses, and resistance of Nile tilapia, Oreochromis niloticus to Plesiomonas shigelloides. Fish and Shellfish Immunology, 84, 1125-1133. https://doi.org/10.1016/j.fsi.2018.11.012

Zakaria-Rungkat, F.. Nurahman, Prangdimurt, E., \& Tejasari (2003). Antioxidant and immunoenhancement activities of ginger (Zingiber officinale Roscoe) extracts and compounds in in vitro and in vivo mouse and human system. Nutraceuticals and Food, 8, 96-104. https://doi.org/10.3746/jfn.2003.8.1.096

Zemheri-Navruz, F., Acar, U., \& Yilmaz, S. (2019). Dietary supplementation of olive leaf extract increases haematological, serum biochemical parameters and immune related genes expression level in common carp (Cyprinus carpio) juveniles. Fish and Shellfish Immunology, 89, 672-676.

https://doi.org/10.1016/j.fsi.2019.04.037 